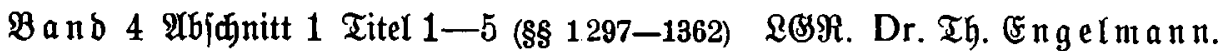

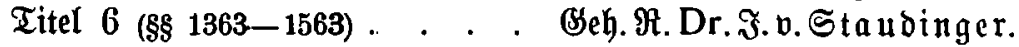

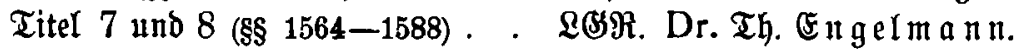

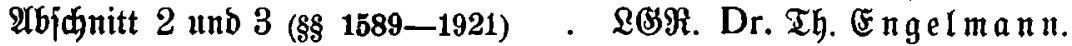

$\mathfrak{B a n b} 5$ $\mathfrak{B} \mathfrak{a} \mathfrak{n} 6$

Die rebattionelle Leitung bes \&ejamtwertes führte bis zu feinem im Februar

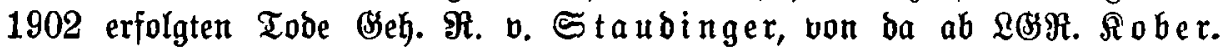
$\mathfrak{M}$ ü nde $\mathfrak{n}$, im März 1903.

\title{
Die Gerrausgeter.
}

\section{Dorwort jur 2. Iuflage.}

Die Biele und Zwecte ber neuen $\mathfrak{a}$ uflage gehen über bie ber erjten erheblid hinaus. Währeno es fid bei biejer vielfady nur um marfante Dariftellung ber

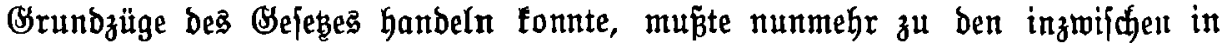
getwaltiger $\mathfrak{A} \mathfrak{n} z \mathfrak{h l}$ aufgetaudten (Einzelfragen Stellung genommen werden. Dak bie ermeiterte $\mathfrak{A} u f g a b e$ eine völlige $\mathfrak{u m g e f t a l t u n g}$ einzelner $\mathfrak{I}$ eile erforberlid

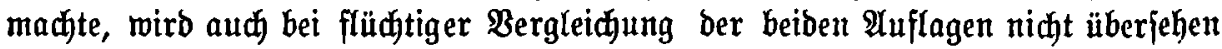
werbell fönuten.

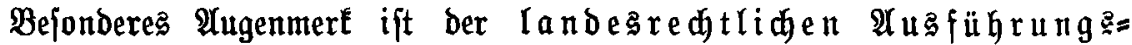

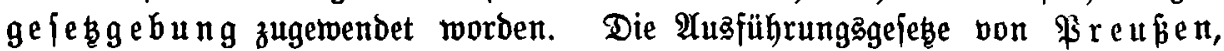

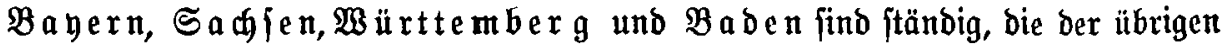

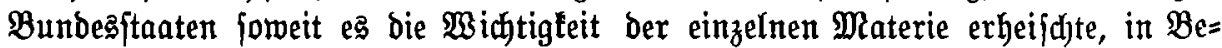

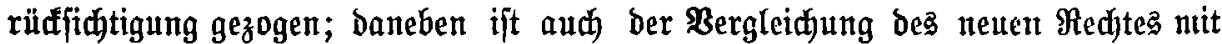

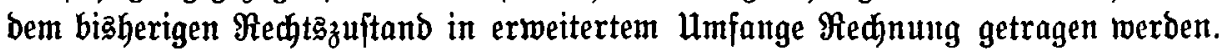

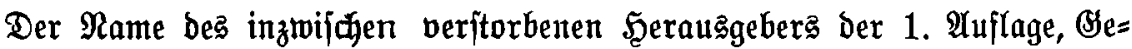
heimrats von Staubinger, foll audh fernerhin bem $\mathfrak{W e r f e}$ erhalten bleiben. Bon ben in eriter $\mathfrak{A}$ urflage Durđ (Geheimrat von Staubinger erläuterten Materien miro nummehr bas ehelide Büterredft von Lanogeridhtzarat Dr. Engelmann, Der bem Dbligationenredyt angehörende Teil von Sandgerichtảrat $\Re \mathfrak{o b e r}$ be=

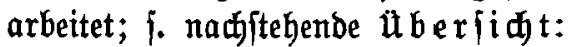

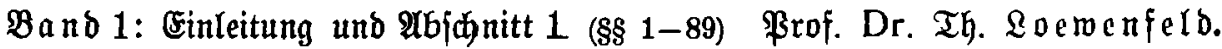

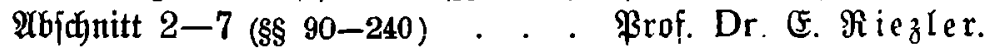




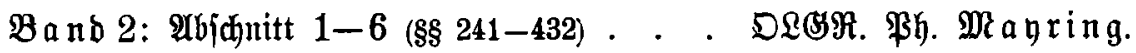

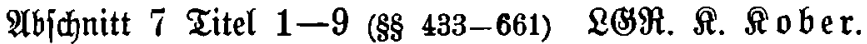

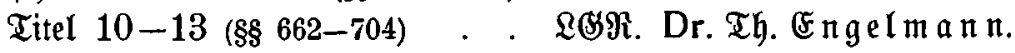

Titel 14 und $15(\$ \S 705-758)$. $2 \mathfrak{R} \Re$. . $\Re$ ober.

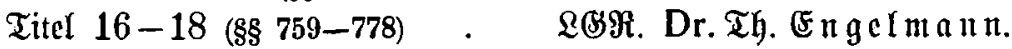

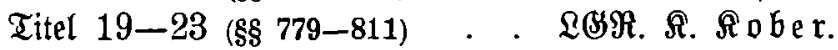

Titel 24 und 25 (\$8 812-853) . $\quad$ \&Sß. Dr. Th. Engelmann.

$\mathfrak{B a n d} 3$. LGR. $\Re$. $\mathfrak{R} \mathfrak{o b e r}$.

$\mathfrak{B a n d} 4$.

$\mathfrak{L} \Re$. Dr. Th. Engelmann.

$\mathfrak{B a n b} 5$

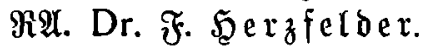

$\mathfrak{B a n d} 6$. DQGR. I. $\mathfrak{\text { agner. }}$

Die rebaftionelle Reitung bes Sefanttrerfés wirb von Randgeridtas=

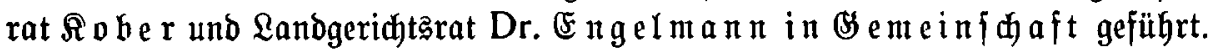

Die nunmehr jebem einzelnen Bande beigegebenen $\Re$ egifter fomie bas

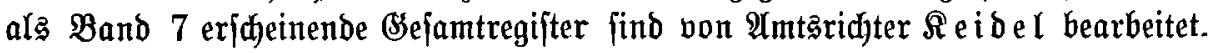

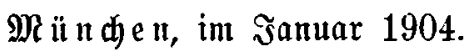

\section{Die Germignelher.}

\section{Dorwort jur 3. unt 4. Iluflage.}

Die zweite $\mathfrak{A}$ uflage war fo furze Beit naw ihrer Fertigftellung vergriffent,

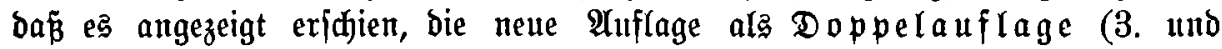
4. $\mathfrak{U}$ uflage) erideinen zu lafjen.

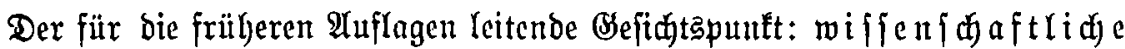
Durdoringung bes Stoffes bei forgfältigjter $\mathfrak{B} \mathfrak{c}$ üafidtigula ber $\mathfrak{B}$ ed ürfniffe der $\mathfrak{B r a x i s}$ war aud für die Reubearbeitung map̃gebend;

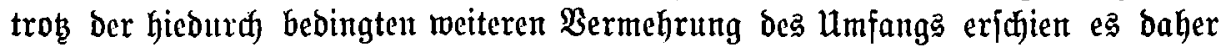
geboten, Die (Ergebniffe ber Siteratur uno Redttipredjung wie bisher mit tunlidjter Bollftänbigkeit ju berüaffiłdtigen.

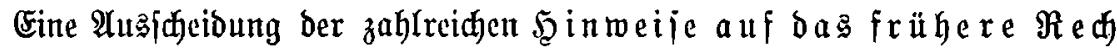

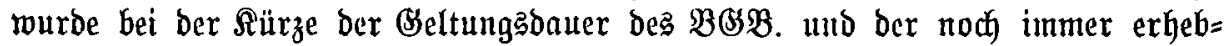

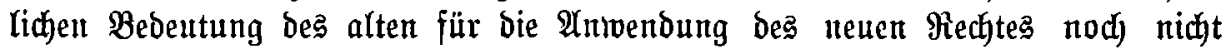
für angezeigt eraftet.

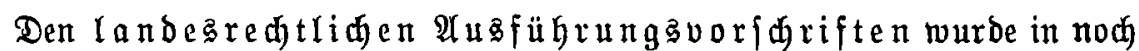

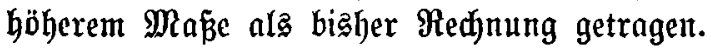

